\title{
Publisher Correction: articles initially published in wrong volume
}

\section{Correction to: Cell Death Discovery}

https://doi.org/10.1038/s41420-018-0065-2

https://doi.org/10.1038/s41420-018-0066-1

https://doi.org/10.1038/s41420-018-0067-0

https://doi.org/10.1038/s41420-018-0068-z

https://doi.org/10.1038/s41420-018-0069-y

https://doi.org/10.1038/s41420-018-0070-5

https://doi.org/10.1038/s41420-018-0071-4

https://doi.org/10.1038/s41420-018-0072-3

https://doi.org/10.1038/s41420-018-0073-2

https://doi.org/10.1038/s41420-018-0074-1

https://doi.org/10.1038/s41420-018-0075-0

https://doi.org/10.1038/s41420-018-0076-z

https://doi.org/10.1038/s41420-018-0077-y

https://doi.org/10.1038/s41420-018-0078-x

https://doi.org/10.1038/s41420-018-0079-9

https://doi.org/10.1038/s41420-018-0080-3

https://doi.org/10.1038/s41420-018-0081-2

https://doi.org/10.1038/s41420-018-0082-1

https://doi.org/10.1038/s41420-018-0083-0 https://doi.org/10.1038/s41420-018-0084-z

https://doi.org/10.1038/s41420-018-0085-y

https://doi.org/10.1038/s41420-018-0086-x

https://doi.org/10.1038/s41420-018-0087-9

https://doi.org/10.1038/s41420-018-0088-8

https://doi.org/10.1038/s41420-018-0089-7

https://doi.org/10.1038/s41420-018-0090-1

https://doi.org/10.1038/s41420-018-0091-0

https://doi.org/10.1038/s41420-018-0092-z

https://doi.org/10.1038/s41420-018-0093-y

https://doi.org/10.1038/s41420-018-0094-x

https://doi.org/10.1038/s41420-018-0095-9

https://doi.org/10.1038/s41420-018-0096-8

https://doi.org/10.1038/s41420-018-0097-7

https://doi.org/10.1038/s41420-018-0098-6

https://doi.org/10.1038/s41420-018-0100-3

https://doi.org/10.1038/s41420-018-0101-2

https://doi.org/10.1038/s41420-018-0104-z

https://doi.org/10.1038/s41420-018-0102-1

https://doi.org/10.1038/s41420-018-0103-0 
https://doi.org/10.1038/s41420-018-0105-y

https://doi.org/10.1038/s41420-018-0106-x

https://doi.org/10.1038/s41420-018-0107-9

https://doi.org/10.1038/s41420-018-0108-8

https://doi.org/10.1038/s41420-018-0109-7

https://doi.org/10.1038/s41420-018-0111-0

https://doi.org/10.1038/s41420-018-0112-z

https://doi.org/10.1038/s41420-018-0110-1 https://doi.org/10.1038/s41420-018-0113-y

https://doi.org/10.1038/s41420-018-0114-x

https://doi.org/10.1038/s41420-018-0115-9

Due to a technical error, content intended for publication in Volume 4 (2018) published in Volume 5 (2019). The content has been moved into the correct volume, and the citation information was updated accordingly.

Published online: 10 July 2019 